\title{
No contexto do não sei: reflexões e dúvidas sobre as juventudes e a educação gaúcha em tempos de pandemia
}

Diana Juciéli Ribeiro ${ }^{1}$ Eduarda Teixeira Streck ${ }^{2}$ Robson Thomas Ribeiro ${ }^{3}$

\begin{abstract}
Resumo:
A pandemia do novo coronavírus, desde o início de 2020, modificou significativamente o cotidiano ao qual estávamos habituados. Ao passo que as escolas precisaram serfechadas, crianças, jovens, famílias e professores entraram num período de inúmeras incertezas frente ao cenário existente. Assim sendo, nesta escrita buscamos refletir sobre os desafios impostos pela pandemia, bem como discutir alguns aspectos que consideramos relevantes no que tange à educação básica atual. Para tanto, analisamos a proposta do Governo do Estado do Rio Grande do Sul, denominada pela Secretaria da Educação do Rio Grande do Sul como "Ensino Híbrido" em relação ao seu desenvolvimento e sua funcionalidade. Neste contexto, assinalamos alguns equívocos entre a proposta das autoridades gaúchas e o Ensino Híbrido, que há décadas faz parte das práticas escolares de países desenvolvidos. Outro tópico que destacamos é a exclusão de boa parte dos estudantes que não possuem meios de acompanhar aulas pela internet. Considerando que o aprendizado se dá por meio da troca entre professores e estudantes, neste texto nos interessa investigar como tem sido estes processos e quais têm sido os maiores desafios ao exercício da docência em contextos de exclusão social e distanciamento intelectual.
\end{abstract}

\section{Palavras-chave: \\ Educação. Pandemia. Ensino Híbrido. Juventudes.}

\section{In the context of I don't know: reflections and doubts about youth's culture and gaúcha education in pandemic situation}

\footnotetext{
Abstract: The new coronavirus's pandemic in the 2020's beginning changed the daily life. While schools needed to be closed, children, students and your families and teachers entered a period of countless uncertainties regarding to context. Therefore, in this text we seek to reflect on the challenges imposed

1 Graduada em Letras, professora da Rede Municipal de Cerro Largo. E-mail: dianajribeiro07@gmail.com. ORCID iD: http://orcid.org/0000-0001-8723-2805.

2 Acadêmica do Curso de Artes Visuais Licenciatura Plena em Desenho e Plástica pela Universidade Federal de Santa Maria. E-mail: eduardastreck@gmail.com. ORCID iD: http://orcid.org/0000-0001-6797-1061.

3 Acadêmico do Curso de Letras Licenciatura - Habilitação: Espanhol e Literaturas da Língua Espanhola na Universidade Federal de Santa Maria. E-mail: robsonthomasrb@gmail.com. ORCID iD: https://orcid.org/0000-0001-7573-746X.
} 
by the pandemic situation and discuss some aspects that we consider relevant to think about basic education in these times. We analyzed the State Government of Rio Grande do Sul proposal, called "Hybrid Teaching" in relation to its development and functionality. In this context, we point out some misunderstandings between the proposal of the gaucho authorities and Hybrid Education. Another topic that we examine is the exclusion of most students that don't have access to internet. Considering that learning takes place through the exchange between teachers and students, we are interested in investigating how these processes have create challenges to the practice of teaching in contexts of social exclusion and intellectual distance.

Keywords: Education. Pandemic-situation. Hybrid Teaching. Youths.

\section{En el contexto del no saber: dudas y reflexiones acerca de la educación gaúcha de los jóvenes en tiempos de pandemia}

Resumen: La pandemia del nuevo coronavirus desde principios de 2020 ha cambiado significativamente la vida cotidiana a la que estábamos acostumbrados. En medio de escuelas cerradas, muchos niños, jóvenes y sus familias igual que los docentes entraron en un período de innumerables incertidumbres respecto al escenario existente. En este artículo buscamos reflexionar sobre los desafíos impuestos por la pandemia e igualmente nos dedicamos a discutir algunos aspectos que consideramos relevantes en torno a la educación básica. Para ello, analizamos la propuesta del Gobierno del Estado de Rio Grande do Sul, denominada por la Secretaría de Educación de Rio Grande do Sul como "Docencia Híbrida" en relación a su desarrollo y funcionalidad. En este contexto, señalamos algunos malentendidos entre la propuesta de las autoridades gauchas y la Educación Híbrida, que ha sido parte de las prácticas escolares en otros países desarrollados hace algunas décadas. Otro tema que destacamos es la exclusión de muchos estudiantes que no cuentan con los medios necesarios para seguir las clases desde la web. Teniendo en cuenta que el aprendizaje se da a través del intercambio entre profesores y alumnos, en este texto nos interesa indagar cómo han sido estos procesos y cuáles han sido los mayores retos para el ejercicio de la docencia en contextos de exclusión social y distanciamiento intelectual.

Palabras-clave: Educación. Pandemia. Enseñanza híbrida. Jóvenes.

\section{E a educação, como está reagindo ao vírus?}

É difícil de responder. $\mathrm{Na}$ atual situação, professores, por de trás de seus computadores, seguem à espera de indivíduos que muitas vezes não sabem quem são. Reconhecem seus nomes, mas jamais conhecerão esses alunos na sua "totalidade". A presença do outro lado da tela é incerta. Não se tem a certeza absoluta de que o aluno está atento, nem mesmo de que está presente. $\mathrm{O}$ estudante passa a ser um ícone, um nome, um número. Assim se configura o atual contexto em que estamos inseridos: a pandemia mundial do covid-19, declarada pela Organização Mundial da Saúde como surto global em janeiro de 2020. Desde então, o que entendíamos como "normal" em nossas rotinas, necessitou de reinvenção, medidas emergenciais precisaram ser tomadas para barrar o avanço do vírus e, no contexto educacional, não foi diferente. Foi necessário buscar meios de seguir com as aulas, mesmo com alunos e professores impedidos de encontrarem-se presencialmente. Nessa busca, as Tecnologias da Informação e Comunicação (TICs) ganharam ainda mais destaque, tornando-se as principais alternativas para o desenvolvimento das atividades.

Num primeiro momento, pensar em professores e jovens utilizando recursos tecnológicos para o desenvolvimento das atividades até então realizadas nas escolas, pode parecer algo até simples, afinal é muito comum relacionarmos a juventude e as novas tecnologias. Entretanto, 
basta uma reflexão um pouco mais aprofundada para compreendermos que em nossa sociedade, tão desigual, nem todos os jovens têm os mesmos recursos ou as mesmas instruções. "Com esse cenário, a educação em época de covid-19 passa a entender a tecnologia como um espaço de luta, transformação, mas também de desigualdades" (BARRETO; ROCHA, 2020, p. 2).

Desde março de 2020, foram-se meses e meses na espera de melhorias, ou até mesmo de respostas seguras em relação às avaliações, aos conteúdos e até mesmo à validação do ano letivo; foi-se um ano inteiro de aulas síncronas e assíncronas, de distanciamento social e de inúmeras dificuldades: como planejar aulas com referências pensadas somente para o ensino presencial? Levando em consideração que o aprendizado acontece por meio da troca de relações (VALLE, 2019), nos perguntamos: quais relações: as presenciais ou as virtuais? Será mesmo que estamos cumprindo e fazendo cumprir o que determina a Base Comum Curricular, no sentido de haver um nivelamento em relação aos conteúdos estudados em todas as escolas brasileiras? Estariam os alunos das escolas privadas e das escolas públicas tendo as mesmas oportunidades neste momento tão delicado? Nesse mar de dúvidas é que surge o "contexto do não sei”...

Em meio a tantas dúvidas em relação a tudo, não apenas à educação, a espera instigante por uma vacina surge com a falsa ideia de que seria ela a solução de todos os nossos problemas. Porém, grande parte dos dilemas revelados no campo da educação não surgiram durante a pandemia, eles apenas agravaram-se e ganharam visibilidade. As grandes mídias deixaram visível aos quatro cantos do Brasil o quanto vivemos em um país desigual. As manchetes diziam "Lave as mãos", ignorando que parte da população sequer possui água limpa, sendo este o principal meio de prevenir a doença. "Fique em casa", determinavam as propagandas, esquecendo da parcela da população que trabalha de dia para comer à noite. Neste contexto, vale recordar das milhares de crianças e jovens que estão sem merenda escolar, alimentação que contribui para a sua sobrevivência. Aliada à pobreza e aos problemas citados, a falta de internet apresenta-se como apenas mais uma das mazelas de crianças e jovens das escolas públicas do país. Falta acesso à internet, faltam equipamentos, faltam ambientes adequados para acompanhar as aulas, falta o cumprimento de inúmeros direitos assegurados por leis, o que acaba ferindo a dignidade da pessoa humana.

De acordo com o Instituto DataSenado, 26\% dos estudantes que estão realizando aulas remotas não possuem acesso à internet (CHAGAS, 2020). Sabemos que estes ganham material impresso da escola para a realização de suas atividades, também temos conhecimento de que existem exemplos de professores que buscaram alternativas variadas para atender a esses estudantes, como é o caso de aulas através do sistema de rádio. Neste sentido, voltamos a refletir sobre a colocação feita pelo autor Lutiere Dalla Valle (2019) a respeito da troca de relações, fundamental para a educação. É imprescindível perguntarmo-nos: quais trocas de relações se estabelecem entre uma folha A4, repleta de conteúdos, e o aluno que consome esse material? Será que o aluno que recebe a aula impressa está conseguindo compreender determinado conteúdo da mesma forma que o estudante que possui acesso à internet? De um lado, estudantes que possuem o momento da aula síncrona, com debates, discussões, troca de dúvidas entre os colegas, compartilhamento de trabalhos, entre outras oportunidades de aprendizagem que o mundo conectado tem a nos oferecer; de outro, estudantes e materiais impressos. Certamente esta realidade não cumpre o que propõe a Base Comum Curricular, estes estudantes de maneira alguma estão tendo um ensino "padronizado", igualitário.

O autor José Roberto Pereira Peres (2017, p. 34) afirma que "A ideia de uma base nacional comum curricular não contempla a diversidade brasileira e não solucionará os problemas educacionais existentes, pelo contrário, potencializará as desigualdades educacionais já existentes". Podemos concluir que é exatamente o que estamos vivenciando, afinal o documento apresenta exigências impossíveis de serem cumpridas no cenário atual, pois não foi pensado para contemplar a gama da diversidade de estudantes brasileiros, muito menos em situações de calamidade pública, como uma pandemia. 
Se antes, no ensino presencial, o proposto pela Base Nacional Comum Curricular (BRASIL, 2017) já não se cumpria em sua totalidade, agora com a pandemia a situação deslanchou, principalmente em consequência de um trabalho de elaboração que possui falhas, incoerências e interferência político-ideológica. O documento parte do pressuposto de que todos os estudantes brasileiros possuem a mesma condição de atingir objetivos, fato que fortalece a ideia equivocada da meritocracia num país tão desigual quanto o Brasil.

Indícios como componentes curriculares privilegiados em detrimento de outros, "normas" a serem aplicadas independente dos contextos nos quais as escolas estão inseridas, preparação de alunos/indivíduos para o mercado de trabalho e desvalorização das subjetividades, são marcas que explicitam que a Base Nacional Comum Curricular (BRASIL, 2017) não faz jus às palavras que traz em seu nome.

\section{Ensino Híbrido... Qual?}

A Secretaria de Educação do Estado (Seduc) do Rio Grande do Sul adotou como medida para a realização das atividades não presenciais o que denominou de "Ensino Híbrido", termo que embora já fosse utilizado em inúmeros estudos referentes à educação, difere-se em muitos aspectos do que apresentou a proposta do órgão responsável pela educação gaúcha. O "Ensino Híbrido" começou a ser implementado em julho de 2020, meses após o surgimento dos primeiros casos de infectados pela covid-19 no Rio Grande do Sul e, por consequência, do fechamento das escolas, em março de 2020.

O conceito de Ensino Híbrido ${ }^{1}$, prévio à modalidade proposta pela Seduc RS, contempla as chamadas metodologias ativas em educação, e nada mais é do que a divisão entre o ensino não presencial e o ensino presencial, este que pode acontecer em sala de aulas, laboratórios e demais espaços escolares. Neste modelo o professor atua como um mediador, um catalisador do conhecimento, enquanto os alunos estudam determinado conteúdo através das tecnologias (games, aplicativos, plataformas...) no período não presencial, este estudo pode ser em grupo ou de forma individual. $\mathrm{O}$ espaço da sala de aula é reorganizado, não mais o professor ocupando o papel principal, com os estudantes sentados enfileirados, apenas recebendo informações. $O$ aluno possui uma autonomia maior, pois através das tecnologias desenvolve seu aprendizado e no momento do ensino presencial irá expor suas descobertas, dúvidas e aprendizados, socializando com a turma e com o professor. O estudante torna-se o protagonista dos processos de ensino-aprendizagem. Dessa forma, com a sala de aula invertida, a participação dos estudantes no momento presencial torna-se mais efetiva, já que cada indivíduo traz consigo algum conhecimento sobre o assunto que será abordado em sala de aula.

Muitas escolas espalhadas pelo mundo desenvolvem a metodologia do Ensino Híbrido, países situados principalmente no continente europeu, são exemplos de sucessos com o uso das tecnologias, como é o caso da Finlândia, que possui índices altíssimos de rendimento, permanência e conclusão do ensino básico. No Rio Grande do Sul as matrizes curriculares publicadas em 7 de agosto de 2020, caracterizam o ensino que hoje estamos vivenciando como Ensino Híbrido, porém no site do governo do estado aparece também o termo "aulas remotas", deixando evidente que a noção de Ensino Híbrido adotada pela rede estadual de ensino do Rio Grande do Sul, está longe de ser similar ao Ensino Híbrido realizado em escolas estrangeiras a partir dos anos 60.

\footnotetext{
1 “Híbrido significa misturado, mesclado, blended. A educação sempre foi misturada, híbrida, sempre combinou vários espaços, tempos, atividades, metodologias, públicos. Agora esse processo, com a mobilidade e a conectividade, é muito mais perceptível, amplo e profundo: trata-se de um ecossistema mais aberto e criativo. O ensino também é híbrido, porque não se reduz ao que planejamos institucionalmente, intencionalmente. Aprendemos através de processos organizados, junto com processos abertos, informais. Aprendemos quando estamos com um professor e aprendemos sozinhos, com colegas, com desconhecidos. Aprendemos intencionalmente e aprendemos espontaneamente." (BACICH; MORAN, 2015, p. 45).
} 
No Rio Grande do Sul, a plataforma Google Classroom foi adotada pelas escolas públicas, porém é inegável que tal plataforma não consegue contemplar as mínimas características que definem o Ensino Híbrido, pois o aluno ainda não está no centro da aprendizagem e as metodologias de ensino acabam sendo as tradicionais. Neste sentido, "o educador é o que diz a palavra; os educandos, os que a escutam docilmente; o educador é o que disciplina; os educandos, os disciplinados" (Freire, 2005, p. 68), e ampliando para o atual contexto, segue-se o recorrente modelo de educação bancária, o professor é o que envia a atividade, o aluno responde; o professor é o que marca a reunião no Google Meet, passa o conteúdo "desconhecido" dos estudantes e depois aplica uma atividade: o ciclo se repete porém as terminologias são modificadas.

Temos ciência de que a escolha do termo do Ensino Híbrido possui também força política, pois, subentendemos que num futuro próximo, alunos e professores voltarão às salas de aula, sendo então possibilitada a implementação do Ensino que será ora presencial, ora não. Em outubro de 2020, o governador do Rio Grande do Sul, Eduardo Leite, declarou:

Desde o final de julho, observamos uma estabilização da velocidade de transmissão e das internações por coronavírus nos leitos de UTI do Estado. Desde setembro, observamos a redução das internações e do número de óbitos. Nossos dados mostram claramente que o RS já atravessou o pior momento e vive uma situação mais controlada, com a população consciente dos cuidados que devem ser tomados e, portanto, podemos dar passos importantes na retomada das atividades. (PORTAL DO ESTADO..., 2020).

Aliado ao discurso do Governador, foi autorizada a retomada de atividades em muitas escolas particulares, as quais tiveram condições de comprar equipamentos e comprovaram estar dentro das normas propostas por órgãos estaduais. Entretanto, é inegável que a fala de Eduardo Leite abranda a situação pandêmica, como se tudo se encaminhasse para uma melhora significativa, $o$ que é muito distante da realidade que estamos enfrentando, atualmente em janeiro de 2021, com UTIs lotadas, recordes de mortes e infectados.

Nesse contexto, o ensino, chamado de híbrido pelo governo, nada mais é que um ensino remoto orientado pelos professores. O Ensino Híbrido, como já exposto, é uma tendência da contemporaneidade, com potencial real para a melhoria da educação, porém o Brasil, ocupando a sétima posição na lista dos países mais desiguais do mundo, com um aumento de $67 \%$ da população vivendo em extrema pobreza, não possui (na realidade pré-pandêmica, nem na atual) condições possíveis para esta implementação. Preocupa-nos ainda o fato de que esta modalidade de ensino, se implementada no período pós pandêmico, dificultará ainda mais a aprendizagem e proporcionará o aumento significativo das desigualdades em nossa sociedade, já tão plural em realidades e condições.

Além do mais, é fundamental entendermos que o letramento digital se faz necessário para o bom desenvolvimento do Ensino Híbrido, envolvendo não só a capacidade de leitura e escrita nos meios digitais, como a utilização desses recursos de forma consciente, filtrando informações e localizando-se na imensidão da rede.

É necessário que os educadores sejam capazes de mediar as relações entre os alunos e esses espaços virtuais, conhecendo minimamente a linguagem da rede, os códigos e imagens que constroem estes universos. É indispensável que os professores sejam letrados digitalmente, pois quando entendemos como um dos papéis da escola a educação de indivíduos de maneira integral, a fim de que estes desenvolvam capacidade para solucionarem os problemas que venham a ocorrer no seu cotidiano, é fundamental que possamos construir capacidades digitais nestes alunos, levando em conta que atualmente somos totalmente dependentes das tecnologias digitais. Inclusive, aprender a desfrutar do que a tecnologia tem a oferecer é importante, ainda, para desenvolver a criticidade nestes jovens estudantes, no que se refere ao uso e manejo conscientes dos meios digitais, como dito anteriormente. 
É pontual, portanto, a atuação dos educadores na mediação destas relações de ensino e aprendizagem em rede, antes mesmo que elas se realizem, de forma que os educandos sejam instigados a analisar dados, informações e subjetividades intrínsecas, proporcionando uma maior reflexão acerca dos conteúdos que consomem no meio digital, pois não basta saber utilizar um computador ou um celular e viajar pelo mundo das redes sociais e dos jogos, é preciso interpretar criticamente o "boom" de informações que recebemos a cada segundo por meio da internet. Todavia, esta não é a realidade que enfrentamos: grande parte dos alunos que estudam na educação básica não tiveram este contato prévio e acompanhado de um ensino mediado por tecnologias digitais.

De fato, dependendo da realidade escolar com a qual vamos interagir, há muitos nativos digitais, principalmente se analisarmos as faixas etárias que compõem as séries finais do Ensino Fundamental e o Ensino Médio, compostos, em boa parte, por adolescentes e jovens, que muito antes da pandemia já estavam familiarizados com aparelhos celulares. Por outro lado, temos inúmeras outras realidades que estão marginalizadas dessa sociedade digital. Nesse sentido, afirmar que nascidos a partir de determinada década são nativos digitais é ignorar que nem todas as pessoas têm acesso a esse direito humano e, nessas situações, fica à escola a função de proporcionar vivências digitais variadas aos estudantes.

Não é só possível, como necessário, que se trabalhe a partir da teoria dos multiletramentos ${ }^{2}$ em que está inserido o letramento digital, para que haja uma educação integral. É fundamental que se trabalhe outras possibilidades de letramento no sentido de que os enunciados partam de múltiplos pontos e possam expressar diferentes formas de letramento, desde as mais formais ou tidas como convencionais, às mais corriqueira e populares, potencialmente as produzidas na rede que a cada vez mais não se separam da experiência social humana, a fim de que os alunos consigam estabelecer sentidos aos textos e às imagens nas mais diversas situações e espaços.

Porém é interessante questionarmos: quantos são os educadores realmente letrados digitalmente ou que têm a possibilidade de uma formação continuada que possibilite suprir estas demandas?

Há que se considerar que talvez muitos professores não possuam, por vários motivos inerentes à sua vontade, as competências necessárias para trabalhar a partir das abordagens dos multiletramentos e letramento digital, tão necessárias no Ensino Híbrido. Podem estes educadores não disporem de tempo ou mesmo de condições de várias naturezas para uma formação continuada que atenda a essa demanda. Também é importante compreender que embora haja diversas propostas teóricas desenvolvidas acerca de um modelo menos centralizador do papel do professor, a realidade é que estes profissionais muitas vezes não conseguem se desprender dos modelos mais tradicionais e pouco horizontais de ensino. Tal problema, já sistemático, afeta a estrutura da educação brasileira e para que estas outras propostas pedagógicas como o Ensino Híbrido sejam efetivas é necessário que o aluno seja autônomo, um agente do seu próprio letramento, que consiga construir seus próprios significados a partir de textos, imagens, entre outros, e por conseguinte, possa refletir e levar para as relações de ensino-aprendizagem propostas de letramento que tenham passado despercebidas à prática do professor. A partir dessa, por enquanto, sonhada troca, estariam sendo possíveis novas experiências aos indivíduos inseridos no ambiente escolar e até mesmo novas perspectivas à prática docente dos professores em questão.

De fato, aprender a fazer algo diferente do que se faz há anos, requer formação continuada, espaços de reflexão, diálogo e troca entre colegas. Os professores da escola, como sabemos, pouco são incentivados a essas práticas de formação. Se faz urgente, portanto, o desenvolvimento de políticas públicas que fomentem a formação continuada, e, neste sentido, que incentivem os professores a 
atualizarem-se em relação às tecnologias, afinal nossa sociedade se transforma muito rapidamente. Um professor com uma formação alinhada ao contexto atual poderá entender a necessidade de desenvolver nos alunos a autonomia, propondo que sejam agentes do seu próprio letramento, para que, a partir desta construção de autonomia e desenvolvimento, sejam minimamente preparados para as novas possibilidades que introduz o Ensino Híbrido.

É inegável que os meios virtuais e as ferramentas digitais trazem muitas vantagens e benefícios às relações de ensino-aprendizagem, contribuindo muito com a construção intelectual dos usuários, dispondo ferramentas que nos permitem suprir necessidades que antes seriam impossíveis sem equipamentos caros e softwares pagos. Hoje, por exemplo, podemos criar podcasts em nossos celulares (com aplicativos de gravação, edição e tratamento de áudio gratuitos) e compartilhá-los na rede, tornando-os disponíveis ao mundo todo. No sentido da educação formal, esta nova forma de difundir conteúdo dinâmico através da internet, oferece muitas alternativas que potencializam o ensino e a socialização de produtos da educação.

Os caminhos e as possibilidades geradas por estas transformações no modo de gerir as tecnologias de rede impactam de maneira muito positiva o campo do ensino, todavia, é importante que não depositemos sobre elas a certeza de sucesso ao exercício educacional, pois o processo de aprendizagem envolve uma infinidade de aspectos e necessidades, que vão desde questões didático-pedagógicas até questões estruturais do sistema educacional, da própria organização do tecido social e da realidade de cada instituição de ensino e de sua comunidade escolar.

Por isso, ao se pensar em práticas escolares, devemos visualizar uma realidade que não é única ou homogênea; que, pelo contrário, varia muito de escola para escola, e de indivíduo para indivíduo. Nesse contexto tão diverso, as tecnologias digitais podem e devem auxiliar, sendo um dispositivo para impulsionar as descobertas e aprendizados de cada aluno. As tecnologias digitais são tomadas, utilizando o termo de Corazza (2016), como "trampolins", que nos fazem "saltar" e conhecer o desconhecido. Por isso, reforçamos que a escola deve ser o meio democrático para se trabalhar com o desenvolvimento do letramento digital, não apenas dos professores, mas também dos alunos, ampliando a sua atuação para que propostas mais fluídas, como é o caso do Ensino Híbrido, sejam realmente agregadoras e tragam transformações significativas e benéficas para o ensino. Deve ser a escola, inclusive, a responsável pela "socialização política" ${ }^{3}$ dos jovens, formando cidadãos críticos que possam lutar para construirmos uma sociedade mais incluída digitalmente, com internet para todos, em comunidades rurais, periferias e bairros, de forma gratuita, universal e com qualidade.

\section{E as juventudes, onde estão?}

Neste ínterim de pandemia, Ensino Híbrido, falta de letramento digital, profissionais da educação, pais e responsáveis esgotados, então os estudantes, atuando como meros coadjuvantes nessa história toda. A eles, uma realidade na qual o direito de ensino gratuito e de qualidade não está sendo cumprido em sua totalidade. Embora ainda não existam dados oficiais sobre evasão escolar durante a pandemia, sabe-se que muitos jovens acabaram abandonando os estudos. Onde estão essas juventudes? A Base Comum Curricular (2017, p. 12) nos alerta da importância de acolher as diversidades, ambiciona ainda que estes jovens sejam protagonistas de seus projetos de

\footnotetext{
3 “A relação entre socialização política e juventude parece inicialmente tácita. Afinal, parece uma obviedade que política e juventude só se articulem pelo fato de que os jovens ainda não estejam completamente preparados para a atividade política, e sua participação política esteja condicionada a um processo de credenciamento. Portanto, o conceito de 'socialização política' indica, num primeiro plano, o processo de preparação ou habilitação que se faz necessário para que os jovens possam participar da atividade política. [...] 'Socialização' é uma noção cara aos estudos na área da juventude e da infância como um todo, e diz respeito aos processos de aquisição de habilidades e atitudes que credenciam determinado sujeito ao exercício ulterior de uma função ou atividade (Jahoda, 1996)" (CASTRO, 2009, p. 480).
} 
vida, "promovendo o respeito à pessoa humana e aos seus direitos". Infelizmente a realidade que vivenciamos é totalmente ao contrário, sendo o abandono escolar durante o Ensino Médio uma realidade brasileira de anos, que a pandemia ajudou a agravar, repercutindo principalmente nas classes menos privilegiadas.

Quem são estes jovens que enfrentam problemas diversos para a permanência na escola, formando o grande contingente de evasão escolar nos últimos anos da educação básica? A grande taxa de evasão está estreitamente relacionada a diversos outros problemas sociais, tais como o desemprego, a pobreza, a dependência da assistência pública, os problemas de saúde, a criminalidade, a apatia política e social, entre outros. Dados do IBGE de 2015, apontam um crescimento potencial no percentual de evasão entre jovens de 15 a 17 anos, ao ponto que decresce a renda per capita domiciliar destes estudantes. Embora, muitas vezes, deixar a escola, para um jovem de família pobre é a possibilidade de alcançar alguma independência econômica ou a possibilidade de ajudar os seus nas despesas de casa, o futuro que aguarda uma pessoa que abandonou a escola tem tudo para ser marcado por pobreza e exclusão social. Como apresenta a professora de biologia Joseline Souza Nascimento, em uma entrevista de junho de 2020 à BCC News Brasil (IDOETA, 2020),

Muitos são filhos de pais autônomos, como pedreiros ou pescadores. Alguns até têm celular para assistir às aulas, mas estão trabalhando manhã e tarde. Com certeza dá medo de eles não voltarem, pelo impasse (de perder a renda extra) e pela ideia de 'não vou conseguir aprender mais'.

As possibilidades que o sistema educacional Brasileiro ofereceu e as ações tomadas para o segmento do ano letivo em meio à pandemia do novo coronavírus, possivelmente trarão desdobramentos permanentes à educação. É pertinente refletirmos: será que as medidas tomadas acolhem estes jovens em condição de pobreza ou os invisibilizam? Há que observar dois pontos em específico: 1. A situação precária de vida de grande parte desses jovens; 2 . A capacidade da educação básica em atender estes jovens e lhes dar possibilidades e recursos para a transformação de sua realidade.

\section{A situação precária de vida de grande parte desses jovens:}

O que visualizamos no panorama nacional é grave e aterrador. Estamos postos de frente para a prática escancarada do "juvenicídio", que ganha força com os desdobramentos causados pela pandemia e a falta de acesso que as populações mais pobres enfrentam. Muito além de matar jovens, o estado brasileiro, sob comando e aval de suas próprias instituições, investe em desferir, sem pudor, um golpe fatal em qualquer embrião que possa gestar um projeto de vida digno aos mesmos, o faz ampliando o desmonte sistemático sob as áreas da cultura, educação, ciência, esporte e geração de trabalho e renda. A juventude brasileira, potencialmente a periférica, vive sob a mira de uma arma de duas balas, uma que acerta em cheio a sua carne e outra que, de tocaia, atinge silenciosamente os seus objetivos e planos.

\section{A capacidade da educação básica em atender estes jovens e lhes dar possibilidades e recursos para a transformação de sua realidade:}

A ineficiência da educação em transformar essas realidades, é fato, se dá de maneiras simples quando reforça os mecanismos de criação de identidades desacreditadas. Todos conhecemos ou ouvimos falar de um "aluno problema", aquele que "não tem mais jeito". No contexto da pandemia,

40 "juvenicídio", como propõe José Manuel Valenzuela (2015), quem inaugurou o termo, é a prática de precarização da vida dos jovens expostos a uma condição de vulnerabilidade social e que, por conseguinte, são lidos pela comunidade que estão inseridos, como identidades desacreditadas. Toda a precarização da vida desses indivíduos, que se agrava quando observamos a partir das perspectivas sociais de gênero e raça, desemboca nas políticas higienista de limpeza social, que no Brasil e em toda a América se camuflam num plano de combate às drogas, que em verdade é uma guerra anunciada contra as populações pobres e periféricas, constituídas majoritariamente por pretos e pardos. 
ao nos depararmos com um panorama que institui um sistema híbrido, sem levar em conta a realidade de milhares de jovens que não possuem acesso às novas tecnologias digitais, ou internet, ou ainda possibilidades de gerir minimamente ferramentas tecnológicas, fomentamos a exclusão.

Se atentarmos o olhar para as raízes desta questão, visualizaremos falhas do sistema educacional, como a falta de políticas públicas de integração de comunidades em vulnerabilidade ao convívio escolar, o que por conseguinte esbarra em um enorme percentual de evasão escolar. Neste sentido, surgem algumas inquietações: o sistema educacional, como um todo, diante das propostas do período pandêmico e previsões para o pós-distanciamento social, poderá possibilitar um outro panorama e uma nova possibilidade de transformar a vida destes jovens atacados pelo sistema, ou apresentará uma proposta que caminhe entrelaçada com a manutenção da marginalização e exclusão destes indivíduos, os deixando ainda mais distanciados dos espaços de construção e socialização política?

Um jovem que busca existir para a sociedade jamais se sentirá amparado e visível para uma educação que não o contempla, que não o inclui no processo de aprendizado, sentindo-se responsável por um problema ao qual não é o culpado de existir. De acordo com a pesquisa do Data Folha, publicada em julho de 2020, no jornal Folha de São Paulo,

Com a crise econômica provocada pela pandemia do novo coronavírus e a suspensão das aulas presenciais, $31 \%$ dos pais de alunos de escolas públicas do país temem que os filhos não continuem na escola. Além da necessidade de trabalhar, os responsáveis também apontam a falta de motivação como fator que pode levar ao abandono escolar. (PALHARES, 2020).

Se pensarmos que tantos jovens não possuem acesso à internet, logo chegaremos à conclusão, ainda que superficial, de que grande parte destes jovens não está acompanhando o ano letivo, ou quando muito está acompanhando através de uma folha $\mathrm{A} 4$, impressa por uma escola que não recebeu verba extra no período de pandemia para imprimir materiais que ao menos fossem mais interativos, propondo uma troca entre o texto escrito do professor e o aluno, o que certamente potencializaria uma construção mais transversal do conhecimento.

A curto prazo não há nada que demonstre para este jovem que vale mais a pena estudar do que abandonar a escola em troca de um emprego. Nem mesmo o modelo instalado dialoga com este jovem, e não é de hoje que a construção vertical e por conseguinte liberal da educação, a torna um não lugar para as juventudes. A rua ensina e, de fato, a educação não consegue dialogar com as realidades que povoam as ruas, tampouco com as múltiplas representações identitárias das juventudes que buscam na rua o seu refúgio e a sua escola.

Provavelmente, os mesmos jovens que têm negado o direito à educação e que, por conseguinte, têm na educação um não lugar, são os jovens que depois sofrerão com o desemprego estrutural, com a falta de oportunidades e, quando não mortos, ocuparão as celas de penitenciárias lotadas, sendo privados de direitos básicos. O rapper Criolo (2014), por meio de uma de suas canções, apresenta a frase: “Se eu não existo, porque cobras de mim?". Basicamente é o que acontece, é a invisibilização do jovem e o esforço do sistema, como um todo, para impossibilitar que este jovem se torne visível. A ele tudo é negado, porém o "preço" de sua existência é cobrado, as instituições o tratam como não indivíduo, porém a qualquer ação que transgrida a lógica social das elites brasileiras, quando não o simples fato de (re)existir, é cobrado de maneira punitivista, através de uma política judicial que busca punir e excluir da sociedade estas identidades dadas como desacreditadas, ao invés de buscar a resolução destas questões no cerne do problema.

A educação, de maneira genérica, e as pessoas que a promovem, muitas vezes, de modo estrutural e sistemático, sem uma racionalização mais profunda, repassam demandas e se eximem destes problemas. Embora, sabemos que não se tem recursos e possibilidades de criar ambientes escolares mais receptivos, a própria prática diária conserva estes valores punitivos, a 
responsabilização total das próprias vítimas do sistema, a transmissão de responsabilidades que atravessam ações de punição e distanciamento destas juventudes dos espaços de aprendizagem. De fato, é difícil que estas situações não aconteçam, tendo em vista o sucateamento que há anos a educação vem sofrendo e a sua construção verticalizada, que se organiza seguindo as regras e exigências do mercado. É até curioso pensar que um sistema educacional que se comporta seguindo as demandas do capital, perca alunos em formação para o próprio mercado, antes mesmos destes receberem o seu diploma.

Neste limbo dos espaços demarcados pela educação brasileira, dois lados ocupam um não lugar, sendo vulneráveis e desamparados, tendo seus problemas individuais somados à precarização do ensino. De um lado está o professor, com salários defasados, desrespeitado pelo estado, pelas famílias, pelos próprios alunos, igualmente perdidos. De outro, estão juventudes empobrecidas; sem perspectivas, com medo, desacreditadas e incomodadas com o sufocamento de suas identidades, querendo ser vistas. Dois extremos desgastados, em meio a uma crise sem presentes, postos em embate, duas classes que deveriam estar juntas no desenvolvimento da educação e na luta por um futuro melhor, mais justo e igualitário.

Entre ambos os lados, a crescente de um abismo, um "oco" advindo da dificuldade de diálogo e de aproximação, que se atenuou com a necessidade inevitável de se trabalhar virtualmente. $O$ ensino remoto, que possibilitou para alguns o seguimento do ano letivo, para outros se mostrou incapaz e insuficiente, provocando desânimo e motivando desistências. Infelizmente, as soluções advindas com o ensino remoto, mais uma vez, esqueceram aqueles jovens que mais necessitam de amparo do estado. Por conseguinte, realidades de marginalização dos meios digitais e do acesso à internet, somente nos mostraram o quanto é impossível, na atualidade, a implantação de uma educação nos moldes do Ensino Híbrido para as realidades brasileiras.

Frente a todos estes apontamentos, parece utopia pensar em uma educação mais transversal e acolhedora às juventudes em situação de vulnerabilidade. A realidade de jovens que convivem com problemas como o preconceito social e racial, a violência, as drogas, a marginalidade e a fome, respinga no cotidiano da sala de aula. Os estudantes trazem consigo toda uma carga de conhecimentos prévios e de vivências, nem sempre positivas, que interferirão no modo como os professores desempenharão suas funções. É necessário ao professor o respeito às diversidades e a coragem para buscar, dentro de sua atuação, contribuir para a construção de novas realidades, nas quais os jovens excluídos sintam-se aptos a sonhar e a realizar, por meio da educação.

A tarefa é árdua e cabe refletirmos: de onde este professor buscará, sob a pressão de uma profissão desrespeitada, a estabilidade para propor planos de ensino que formem jovens críticos e autônomos? O questionamento torna-se ainda mais necessário no contexto pandêmico, no qual se enfatiza a exclusão de muitos alunos dos meios virtuais, sendo o único contato entre professores e estudantes o que acontece através de uma fotocópia com textos e "listas" de atividades, que em muitas das vezes sequer voltam para a escola. Nessa realidade, nem ao menos sabe-se o porquê de tal aluno não realizar as atividades, qual é a sua situação, se ele está bem e se está alimentado (tendo em vista que no momento este não tem acesso a merenda escolar).

Frente ao exposto, entendemos que cabe a nós, profissionais da educação, buscarmos alternativas de construir uma nova geopolítica da educação em que o entendido como margem possa ocupar o centro de uma outra história de viabilidades. É importante, portanto, que nós, promotores da educação, possamos deixar explícito e demarcar, em nosso discurso e ação, que não aceitaremos a ampliação deste sistema de exclusão e marginalização, que impõem a cidadãos em pleno desenvolvimento a alcunha de identidades desacreditadas. Afinal, embora o sucesso ou o insucesso da educação não dependa apenas da ação dos professores, somos nós, que vivenciamos no cotidiano escolar realidades das mais variadas, que temos propriedade para falar sobre educação e para propor mudanças. 


\section{Reflexões para seguir pensando...}

Podemos considerar, portanto, a partir das reflexões feitas, que vivemos uma falsa resolução de problemas. A proposta de ensino remoto, denominada pelo Governo gaúcho como "Ensino Híbrido", adotada durante a pandemia não apenas é ineficaz a construções mais horizontais das relações de ensino-aprendizagem, como também se mostra excludente. O que se apresentou como uma forma de seguir o ano letivo, mostrou-se incapaz no que diz respeito ao acolhimento daqueles alunos que não possuem acesso à internet e às novas tecnologias digitais, além de ser uma pedra no sapato para grande parte dos professores, pouco preparados para desenvolver planos de aula e executá-los via rede. Houve um desgaste extremo dos educadores, pouco incentivados a uma formação continuada que supra as carências no uso dos TICs para a mediação de aulas online e/ ou presenciais; houve a desorientação dos alunos não preparados previamente para um contato imediato com aulas remotas; houve um alargamento do abismo social que presenciamos no Brasil. Fato que pode ser percebido nas redes sociais, tão cheias de "memes" e charges que dialogam com o contraste existente entre alunos do mesmo país em relação às condições de seguirem acompanhando as aulas no período de isolamento.

Agora seguimos com os mesmos problemas e com planejamentos de um retorno gradual das aulas de maneira híbrida, e por conseguinte, perspectivas de aplicação do modelo no pós-pandemia. Este panorama nos inquieta e deixa perguntas que seguem relutantes assombrando nossos pensamentos, como por exemplo: Estamos preparados para estas pedagogias de ensino?

Para além disso, estamos preparados e pensando em como iremos receber novamente nas escolas os professores, muitos esgotados, cansados, desanimados? E por conseguinte, como iremos resgatar os jovens que ficaram no limbo durante um ano inteiro, em uma luta diária contra os problemas das aulas remotas somados a uma dura realidade extraclasse? Como serão acolhidas as diversas juventudes e, principalmente, os jovens desacreditados, postos de lado em uma "democracia" que os nega o direito à vida em um pacote de cortes na área da cultura, educação e lazer?

Em meio a estes e tantos outros questionamentos, sabemos que o percurso que virá no caminho educacional será tão difícil quanto (ou até mais) ao que vivemos durante o período pandêmico. Agora, porém, detectados os principais problemas, é o momento de pensarmos em soluções que incluam e agreguem, afinal é única e exclusivamente por meio da educação que será construída uma nação mais inclusiva e igualitária.

\section{Referências}

AGUIAR, Marcia Juliana Dias de; FISCHER, Adriana. A pedagogia dos multiletramentos: uma proposta para a formação continuada de professores. Leia Escola, Campina Grande, v. 12, n. 2, p. 116-130, 2012. Disponível em: http:// revistas.ufcg.edu.br/ch/index.php/Leia/article/view/285. Acesso em: 31 jan. 2021.

PORTAL DO ESTADO DO RIO GRANDE DO SUL. Aprendizagem. Porto Alegre: Palácio Piratini, 2020. Disponível em: https://www.estado.rs.gov.br/aprendizagem. Acesso em: 14 dez. 2020.

BACICH, Lilian; MORAN, José. Aprender e ensinar com foco na educação híbrida. Pátio Ensino Médio, Profissional e Tecnológico, Porto Alegre, n. 25, p. 45-47, jun. 2015. Disponível em: http://www2.eca.usp.br/moran/wp-content/ uploads/2015/07/hibrida.pdf. Acesso em: 17 mar. 2021.

BARRETO, Andreia Cristina Freitas; ROCHA, Daniele Santos. COVID-19 e educação: resistências, desafios e (im) possibilidades. Revista Encantar - Educação, Cultura e Sociedade, Bom Jesus da Lapa, v. 2, p. 1-11, jan./dez. 2020. Disponível em: https://www.revistas.uneb.br/index.php/encantar/article/view/8480. Acesso em: 31 jan. 2021.

BRASIL. Base Nacional Comum Curricular. Brasília, DF: MEC, 2017. 
CASTRO, Lucia Rabello de. Juventude e socialização política: atualizando o debate. Psicologia: Teoria e Pesquisa, Brasília, DF, v. 25, n. 4, p. 479-487, out./dez. 2009. Disponível em: http://www.scielo.br/scielo.php?script=sci_arttext\&pid=S0102-37722009000400003. Acesso em: 31 jan. 2020 .

CHAGAS, Elisa. Data Senado: quase 20 milhões de alunos deixaram de ter aulas durante pandemia. Senado Notícias, Brasília, 12 ago. 2020. Disponível em: https://www12.senado.leg.br/noticias/materias/2020/08/12/datasenado-quase-20-milhoes-de-alunos-deixaram-de-ter-aulas-durante-pandemia. Acesso em: 14 dez. 2020.

CORAZZA, Sandra Mara. Base Nacional Comum Curricular: apontamentos crítico-clínicos e um trampolim. Educação, Porto Alegre, v. 39, p. 135-144, dez. 2016.

CRIOLO. Cartão de Visita. In: CRIOLO. Convoque seu Buda. São Paulo: Oloko Records, 2014.

FREIRE, Paulo. Pedagogia do oprimido. Rio de Janeiro: Paz e Terra, 2005.

IDOETA, Paula Adamo. Pandemia deve intensificar abandono de escola entre alunos mais pobres. BBC News Brasil, São Paulo, 23 jun. 2020. Disponível em: https://www.bbc.com/portuguese/brasil-53476057. Acesso em: 17 fev. 2021.

PALHARES, Isabela. Um terço dos pais teme que os filhos abandonem escola após pandemia. Folha de São Paulo, São Paulo, 21 jun. 2020. Disponível em: https://www1.folha.uol.com.br/educacao/2020/07/um-terco-dos-pais-teme-que-os-filhos-abandonem-escola-apos-pandemia.shtml. Acesso em: 17 fev. 2021.

PERES, José Roberto Pereira. Questões atuais do ensino de Arte no Brasil: o lugar da Arte na Base Nacional Comum Curricular. Revista DDAV, Rio de Janeiro, v. 1, n. 1, p. 24-36, ago. 2017. Disponível em: www.cp2.g12.br/ojs/index.php/ revistaddav/article/view/1163. Acesso em: 31 jan. 2021.

VALENZUELA, José Manuel (coord.). Jovenicidio. Espanha: Nuevos Emprendimientos Editoriales, 2015.

VALLE, Lutiere Dalla. A potência edu(vo)cativa da arte contemporânea: desafios e possibilidades. Revista Digital do Laboratório de Artes Visuais, Santa Maria, v. 12, n. 1, p. 82-95, jan./abr. 2019. Disponível em: https://periodicos.ufsm. br/revislav/article/view/37258. Acesso em: 31 jan. 2021.

Data de submissão: 31/01/2021

Data de aceite: 17/02/2021 